Article

\title{
The Uneasy Marriage between Law and Equality
}

\section{Pauline C. Westerman}

Faculty of Law, University of Groningen, Postbus 716, 9700 AS Groningen, The Netherlands; E-Mail: p.c.westerman@rthrug.nl; Tel.: +31-594-540-155

Academic Editor: Robert Johnson

Received: 3 November 2014 / Accepted: 19 January 2015 / Published: 2 February 2015

\begin{abstract}
There are two ways in which the social ideal of equality has found expression in the law: in the principle of equal treatment and in the principle of non-discrimination. In this article the meaning of these two legal principles is analysed, in order to answer the question to what extent they can be said to contribute to equality in the sense of an equal distribution of collective resources. It is argued that whereas the first just requires decision-making to be rule-based, the second principle demands that rules should be based on sound categorical distinctions. Neither of the two can, however, sensibly be linked to equality as equal distribution. The article concludes that the only way to establish such a link is by adding to the principle of non-discrimination "financial resources" as a suspect ground.
\end{abstract}

Keywords: principle of differential treatment; principle of equality; principle of equal treatment; principle of non-discrimination; right to equality

\section{Introduction}

There are two ways in which the social ideal of equality has found expression in the law: in the principle of equal treatment and in the principle of non-discrimination. In national and international legal documents these principles are usually mentioned in one breath as if they are pointing in the same direction. The concepts are, however, logically distinct. In this article I will point out these philosophical distinctions. I will analyse the meaning of these two legal principles, in order to answer the question to what extent they can be said to contribute to equality in the sense of an equal distribution of resources (such as for instance education or health care) and the allocation of financial means. I argue that whereas the first just requires decision-making to be rule-based, the second principle demands that rules should be based on sound categorical distinctions. Neither of the two can, 
however, sensibly be linked to equality as equal distribution of resources. The article concludes that the only way by means of which such a link can be established is the extension of so-called suspect grounds that figure in the principle of non-discrimination. If "financial resources" are added as such a suspect ground, (re)distributive issues can be addressed.

\section{The Principle of Equal Treatment}

If lawyers are asked to define the principle of equality, they usually offer the definition coined by Aristotle [1] and repeated over and over again, that alike cases should be treated alike and unalike cases should be treated unalike.

As Berlin already pointed out [2], the principle has a wide moral appeal. Already very young children protest if they are given less candy than others and demand extra justificatory reasons for such a departure from the principle of equal treatment. But what does the principle mean? Two meanings present themselves:

a. A total amount of $\mathrm{X}$ should be distributed in equal shares;

b. Persons should be treated according to a rule.

The two meanings are often conflated because they come together in examples such as the distribution of candy bars. Suppose a head of a university department has to economize and is confronted with an extra teaching load of $12 \mathrm{~h}$ for which she is not able to hire an extra teacher. Instead she divides the extra load among her 4 members of staff by asking each of them to teach 3 more hours. It is clear that such a head of department is doing two things at the same time:

a. She is distributing the $12 \mathrm{~h}$ in equal shares; and

b. She is treating all members of staff according to the rule that extra workload should be divided equally.

Now it is clear that only in examples as these, where the content of the rule happens to be such that the rule requires equal distribution, equal distribution and equal treatment come together. But where rules have a different content, there is no such link. If we say that all members of the staff are obliged to fill in a certain declaration form, we can only say that they are treated equally in the sense that there is a rule that equally applies to them. Or if we say that trees should be planted two metres from the fence separating one's territory from that of the neighbours, we will be content to say that all trees, whether birches or oaks, are treated equally by virtue of the fact that they belong to the category "trees". There is no trace of distribution here, because the rule that is invoked is not about distribution. So the meaning of equal treatment is only contingently connected to equal distribution.

But the notion of equal treatment is intrinsically dependent on the existence of categories that inform the decision-maker on what is to count as "like" or "unalike" cases. These categories may be invoked by the decision-maker herself. In fact, the head of department is here making the decision to treat all members of staff as belonging to one and the same category. Would she single out one member of staff and absolve that member from extra teaching duties, protests would ensue. These protests are then not about unequal distribution. Unequal distribution is only the result of a prior decision to treat that specific member of staff not as a "like case", namely as a member of staff as all the others. And protests, although they may be inspired by the unequal outcome, are in fact directed 
against this prior decision. The only way for the head of department to justify her exception is then to say that this particular member of staff belongs to a different category, for instance to the category of specifically funded researchers to which rules concerning teaching load do not apply.

So it is the rule with its categorical distinctions that make it possible for us to distinguish "like" cases from "unlike" cases. As Schauer points out, rules thereby not merely help us to discover similarities and differences, but there are simply no likenesses and differences without rules ([3], p. 206). The principle of equal treatment therefore just tells us to proceed by rules. This is why this principle is first and foremost directed to those who apply the rules, not to those who make the rules. Of course, it is possible that those who apply the rules are at the same time the ones that make the rules. The head of department is a case in point. It is important, however, to realize that the principle of treating alike cases alike can only be applied on the basis of some prior decision concerning the relevant categories. It is important to note that in itself, the principle of equal treatment does not tell us which categories should be made, and which rules should be drafted. It only tells the rule-applier that once items are ordered in categories, they should all be treated in the same way. In fact, if our head of department differentiates between blue-eyed and brown-eyed members of staff, distributing the extra workload only among the blue-eyed members, she is still applying the principle of equal treatment, if she treats all blue-eyed members as blue-eyed members. Of course, people might protest against the strange rule she has adopted, but this protest cannot be justified by reference to the principle of equal treatment alone, which only tells us to refrain from arbitrary decision-making and urges us to abide by rules. This induced Hans Kelsen [4], and later Peter Westen [5], to say that the principle of equal treatment is an empty shell, compatible with the grossest injustice. This does not, however, render the principle morally irrelevant. It prohibits arbitrary decision-making and contributes to legal certainty and stability of the social order. But is has no intrinsic connection with fairness in those cases where the categories and the rules in which they figure are unfair. And, as we have seen, it has only a connection with equal distribution of burdens and benefits in so far as the content of the rule invoked happens to require equal distribution.

\section{The Principle of Non-Discrimination}

In order to strengthen the link between equal treatment and justice, the principle of equal treatment should be accompanied by a principle which is directed to the legislator, and which sees to it that the rules themselves are not unfair. Distinctions between blue-eyed and brown-eyed members of staff should be forbidden. The principle of non-discrimination stretches further than the principle of equal treatment in its requirement that distinctions should not be based on so-called suspect (morally irrelevant) grounds as sex, race, religion or age.

By doing so, the principle of non-discrimination reveals a preference for wider rather than smaller categories of human beings. Leaving matters aside whether "birches" or "trees" should be preferred as categories, the principle focusses on distinctions between persons and emphasizes common humanity as a starting-point. It therefore has a wide moral appeal. Common humanity is the default-position. Distinctions within this all-encompassing category should be justified and be proportionate to the aim of the rule. 
The second element of the principle is its connection with human rights. The principle of non-discrimination is therefore usually invoked in charters of human rights. It says that all human beings have a right to be protected by law, and that all have a right to education, food, health care, or family life.

Although it is clear that the principle thus requires inclusion rather than exclusion, it is not clear whether or to what extent the principle is linked to an equal distribution of resources. Of course, we can say that persons should be equally protected by the law or should equally have access to health care facilities, but already Lucas [6] wondered what the meaning of "equal" is here. He considered this meaning as identical with the "all". According to Lucas [7] there is no difference between

a. All persons should have access to health care;

b. All persons should equally have access to health care.

He adds that the term "equally" is mainly rhetorical [8] and that in no way you can deduce from $a$ and $b$ that

c. All persons are equal.

Although I don't share his conservative disgust of egalitarianism, I think that Lucas is right here. In fact the principle of non-discrimination as the assertion of human rights involves three points of consideration:

1. The object of the right (e.g., collective goods, or the absence of governmental interference);

2. The size of membership: who has a right (e.g., only national citizens, or also refugees);

3. The size of the object of the right (a question which can only be raised with rights to positive goods, namely to how much of the collective good one is entitled: basic health care or cosmetic surgery).

But it does not say anything about the overall distribution of health care provisions among the persons who are entitled to health care.

Whereas the principle of equal treatment requires the decision-maker to apply rules, the principle of non-discrimination requires these laws to apply to mankind as a whole and prohibits unjustified distinctions. But neither principle tells us anything about the proper distribution of resources. In order to remedy that shortcoming and to establish a link between the principles and equality, one has to reformulate these legal principles. It is to such reformulations that I now turn.

\section{The Principle of Differential Treatment}

The first possible attempt to reformulation is to change the principle of equal treatment into a principle of differential treatment. So far, the principle has not found legal expression but keeps recurring in many, predominantly feminist, analyses of the principle of quality. The principle of differential treatment is in fact the reverse of the strategy that is adopted by the principle of non-discrimination. Whereas the latter principle, as we have seen, aims at enlarging the categories used, the advocates of a principle of differential treatment argue that categories should be refined and distinctions should be added. The principle of differential treatment starts from the assumption that if men and women are treated alike, important differences are masked or overlooked, and that the result 
of this equal treatment will be a greater inequality. Therefore, we should make the most of Aristotle's second part of the principle and treat unalike cases unalike. It is hoped that the application of the principle of difference will lead to more (substantive) equality [9].

It should be noted that the proposal to differential treatment uses the terms "equality" in two different senses. As a property of a person or a case (as in "like" case) and as a property of the result: namely a state of affairs in which men and women (or for that matter black and white etc.) have equal shares in a certain good (jobs, salaries, public goods, etc.). It is said that the latter meaning of equality can only be ensured by taking into account the different properties of the persons and cases.

But how do we identify unalike cases? Men and women are different in many respects. How to single out relevant respects from irrelevant ones? The problem is here even more serious than in the case of equal treatment. If we are urged to treat cases alike, we may engage in a search for relevant likenesses by exploring the various categories offered by the law, which group the instances together by singling out some features in which the cases resemble each other. But here we are confronted with a multitude of respects in which cases can be said to be unalike. Women and men are not only unalike but they are unalike in many respects. How then to identify the relevant from the irrelevant respects? Rules cannot help us.

Those who advocate differential rather than equal treatment seem to address this difficulty by suggesting that not rules but empirical research should supply an answer: factual inequalities should be taken into account in order to classify cases as unalike. Alike and unalike cases are not taken to be categories defined by the legislator but as empirical statements about social and economic inequalities, that arise as a result of equal treatment.

However, invocation of "the facts" does not help us here. In order to assess what should be counted as relevant factual equalities or inequalities, one needs to adopt a perspective [10], not necessarily a theoretical perspective but at least some sort of conceptual framework which indicates which "facts" and which inequalities are relevant. From one perspective there may exist inequalities which disappear when viewed from another perspective. Should, for instance, the shorter life-expectancy of men be considered an empirical fact to be taken into account in assessing factual inequalities, leading to a proposal to an early retirement-scheme for men? Without a perspective we don't know which inequalities are the important ones. And such a selection is vital, for there are very few cases of equal treatment in which the outcome is not different. We may allocate the same teaching load to two teachers and yet find out that teacher A suffers less than teacher B since A enjoys teaching classes and $\mathrm{B}$ is more disposed to do research. We may deplore the injustice of this equal treatment of two different people but this does not change the fact that both A and B were alike in the (legally relevant) aspect that they are both appointed as University staff with teaching and research duties. So the principle of differential treatment cannot be applied if we lack rules or criteria that tell us which differences are relevant.

The second difficulty, related to the first, is that inequalities in results may give us some indication of which cases should have be seen alike or unalike but this wisdom necessarily can only be acquired with hindsight. It offers the judge no guidance for actual decision-making. Only after the legal and factual consequences of the judicial decision have materialized does the judge know whether the cases should have been perceived as alike or unalike. The principle of differential treatment imposes the 
courts an obligation of results; the principle tells the judge that her decisions are just as long as they contribute to a certain goal (equal distribution of assets) no matter how the judge arrives at that result.

This is a form of what I analysed elsewhere under the heading of "goal-regulation" [11,12], a legislative and regulatory practice which is nowadays common in many European countries. Usually the imposition of the obligation to achieve goals is there addressed to a set of institutions that consequently set out to analyse, concretise and determine the results that should be obtained, relying on a vast amount of empirical knowledge concerning the proper strategies to achieve these results [13]. However for practical reasons the courts cannot be asked to engage in this complex concretisation process. They are therefore only guided by their own intuitions and expectations both on what counts as significant and relevant characteristics and on the possible causal relation between their decision and the legal and factual effects of those decisions.

\section{The Right to Equality}

But not only has the principle of equal treatment been formulated in order to link it with the overall aim of equal distribution of assets and resources. Also the principle of non-discrimination can be reformulated to this effect. And that is by making the most of the notion of a "right to equality". Now the right to equality usually does not mean much more than the right to equal protection by the law, which is identical to the principle of non-discrimination itself. But we might say that equality should be understood as the equal distribution of resources and that it is also possible to claim "a right to equal distribution". If we could substantiate such a right to equal distribution we could say that the judge should weigh this right against other rights. In other words, to refer once more to the head of department I introduced at the beginning of this article: on the basis of such a right we could impose on her the duty not only to abide by rules (the principle of equal treatment) and not only to adopt rules which are as inclusive as possible (the principle of non-discrimination) but to adopt a rule which sees to it that the additional teaching workload should be distributed equally among the members of the department. And this is after all what we want if we advocate the importance of equality.

I don't think, however, that it is a proper use of language to talk about a right to an equal distribution. Equality is not just a collective good such as clean environment or health care facilities. Equality is not a good but a state of affairs, that can only be achieved by a redistribution of resources: resources should be taken away from the privileged in order to make them less privileged and to be allocated to those who are in an inferior position. This means that it is not possible to say that all members of society have a right to equality; since it would entail the proposition that the rich would have a "right" to be deprived from their wealth (or, for that matter, that the dominant race or gender should be deprived from their privileges). And this is clearly not what we intend to say. Rather we intend to say that corresponding to the right of the poor to equality, there is a duty to respect that right on the part of both the government and the privileged citizens. The right to equality therefore cannot be universalized as a right for all citizens [14].

The right to equality can only be universalized if one reformulates the right to equality as a right to live in a society in which resources are equally distributed. Of course, it is possible to reformulate all the rights in such a way: the right to health could then be reformulated as the right to live in a society in which health is accessible to all, etc. But this is an artificial way of articulating rights. A society in 
which everybody has access to health is embodied and implemented in the right to health (and the corresponding duty of the government to honour that right). Formulations like "having a right to a society in which people have rights" therefore state things twice. Moreover, such reformulations of policy-aims and social ideals in terms of rights lead to infinite regress: people have a right to live in a society in which people have a right to live in a society in which...etc.

These puzzles have to do with the fact that equality is not a collective good to which one can have a right. It is a social ideal, a vision of how a society as a whole should be organised. To reformulate such a social ideal as a right necessarily truncates that ideal. As Raz pointed out, rights are too individualistic to give rise to a social ideal (see also [8], p. 202). They formulate one's entitlement to one's own due or to one's own share but have little to say about the overall distribution of assets. Rights are valuable as implementations of that ideal and we might say that indeed values as "freedom" and "equality" only make sense if they are embodied in legal rules entrenching rights. But this is not to say that one can have a right to a certain state of affairs or social ordering, even if it is a very desirable one.

\section{The Duty to Equality}

We have seen that it is difficult to formulate a social ideal in terms of rights. But is it necessary to start with rights? We are accustomed to do so, and - according to the social contract tradition - to derive governmental duties from individual rights rather than the other way round, to derive rights from duties. But we are not compelled to proceed in this order. Once we democratically decided on the desirability of equal distribution of collective assets such as health care facilities and once we are committed to the view that some citizens should not enjoy a larger amount of health care, leaving others with only very basic provisions, we might decide to impose a positive obligation on the state to distribute health care facilities equally among its citizens.

Such a positive obligation is not necessarily implemented by a correlative right to equal distribution. We have seen that such a right is problematic because it cannot be universalised. But there are other avenues open to the legislator who wants to fulfil this obligation. One such avenue is to extend the principle of non-discrimination and to add one more suspect ground for legal distinctions. We might for instance legislate that not only gender, race and religion but also financial resources should from now on be a morally irrelevant ground of distinction. To distinguish categories according to financial resources would therefore require the legislator to adduce very weighty reasons; in just the same way as weighty justificatory reasons should be advanced by anyone who wants to distinguish on the basis of race or religion. By adding "financial resources" to the list of familiar suspect grounds such as gender, race, and religion, one may implement the duty for legislators to organise collective goods in such a way that they are accessible and affordable in equal measure by both privileged and poor members of society.

Good grounds may be adduced for turning income or financial resources into such a suspect ground. Why would one view "gender" as an irrelevant and "money" as a relevant ground? Walzer pointed out that each collective good calls for its proper criteria for distribution; he considered money as a highly irrelevant criterion for determining the allocation of art, health, or knowledge [15] ${ }^{1}$.

\footnotetext{
1 For a critique of this Walzerian view see [16].
} 


\section{Conclusions}

I have argued that the principle of equal treatment is no more than the requirement to decide according to the rules. The principle of non-discrimination adds to this that rules should not differentiate between persons on so-called suspect grounds and should apply to mankind as a whole. The first principle is therefore about consistent rule-application; the second is about just law-making. Neither of the two is linked to equality if we understand equality as an equal distribution of resources.

Efforts to remedy this shortcoming by reformulating the principles are not satisfactory. The proposal to supplement the principle of equal treatment by a principle of differential treatment imposes on the courts the obligation to predict the kind of factual inequalities that will arise as a result of their decision, without offering guidance on what should count as relevant differences. The proposal to add to the list of rights "a right to equal distribution" is equally doomed to failure: one can only have a right to what is one's own, not to a social ideal such as the desirable distribution of collective goods.

But we may, however, proceed the other way round and derive individual rights from governmental duties. If we decide that the government has a duty to share collective goods equally among its citizens, we might be able to derive from this duty the necessity to add "financial resources" to the list of suspect grounds in non-discrimination law. Not only gender and race but also income and finance may then count as grounds on which the legislator is prohibited to differentiate. I don't advocate such an extension of the non-discrimination principle; I only say that if it is (democratically) decided that the social ideal of equal distribution of resources is worth pursuing, this is one way of expressing that decision in a legal form.

Most governments will refrain from doing so. It is much easier to talk about "equal access" to a collective good, thereby implying that true equality is achieved, whereas in fact nothing more is granted than just that all members have access to at least some health care provisions. But as long as one is reluctant to impose an obligation to the state to see to it that resources are distributed equally, we should acknowledge that all reference to equality in law is doomed to remain rhetorical.

\section{Conflicts of Interest}

The author declares no conflict of interest.

\section{References and Notes}

1. Commonly attributed to Aristotle; see his The Nicomachean Ethics. Translated by David Ross. Revised by John L. Ackrill and James O. Urmson. Oxford: Oxford University Press, 1980, V.3. 1131a10-b15 (first published in 1925). However, Aristotle is speaking here more specifically about the distribution of shares.

2. Isaiah Berlin. "Equality." In Concepts and Categories: Philosophical Essays. Edited by Henry Hardy. London: The Hogarth Press, 1978.

3. Frederick Schauer. Profiles, Probabilities and Stereotypes. Cambridge, MA: The Belknap Press of Harvard University Press, 2003.

4. Hans Kelsen. "What is Justice?" In Hans Kelsen, Essays in Legal and Moral Philosophy. Edited by Ota Weinberger. Dordrecht: Reidel, 1973, pp. 1-26 (originally in 1953). 
5. Peter Westen. “The Empty Idea of Equality.” Harvard Law Review 95 (1982): 537-96.

6. John R. Lucas. “Against Equality.” Philosophy 40 (1965): 296-307.

7. "We may call it, if we like, the argument from Equality of Respect, but in this phrase it is the word 'respect' - respect for each man's humanity, respect for him as a human being — which is doing the logical work, while the word 'Equality' adds nothing to the argument and is altogether otiose" ([6], pp. 297-98).

8. A view which is echoed by Joseph Raz. The Morality of Freedom. Oxford: Clarendon Press, 1986, chap. 9.

9. Iris M. Young. Justice and the Politics of Difference. Princeton: Princeton University Press, 1990.

10. This point is raised by Martha Minow. Making All the Difference: Inclusion, Exclusion and American Law. London: Ithaca, 1990.

11. Pauline C. Westerman. "Governing by Goals: Governance as a Legal Style." Legisprudence: International Journal for the Study of Legislation 1 (2007): 51-72.

12. Pauline C. Westerman. "The Emergence of New Types of Norms." In Legislation in Context: Essays in Legisprudence. Edited by Luc J. Wintgens. Ashgate: Aldershot, 2007, pp. 117-33.

13. Anne-Wietske L. E. Enequist. "Self-Regulation on Responsible Care through Quality Management Systems in Elderly Homes." Legisprudence: International Journal for the Study of Legislation 4 (2010): 259-83.

14. Although one might provide arguments in favour of the view that it is in everyone's interest to build a society based on equality: $c f$. Ronald M. Dworkin. A Matter of Principle. Cambridge, MA: Harvard University Press, 1985, chap. 9.

15. Michael Walzer. Spheres of Justice: A Defense of Pluralism and Equality. New York: Basic Books, 1983.

16. Jeremy Waldron. "Money and Complex Equality." In Pluralism, Justice and Equality. Edited by David Miller and Michael Walzer. Oxford: Oxford University Press, 1995, pp. 144-70.

(C) 2015 by the author; licensee MDPI, Basel, Switzerland. This article is an open access article distributed under the terms and conditions of the Creative Commons Attribution license (http://creativecommons.org/licenses/by/4.0/). 